\title{
MENTAL HEALTH CARE FOR CHILDREN AND ADOLESCENTS IN GALICIA (SPAIN) DIFFERENCES BETWEEN DIFFERENT REGIONS IN SPAIN
}

Gago-Ageitos, AM *; Durán-Maseda, MJ*; Vidal-Millares, M*; Josefa Ares-Durán**Carballal-Mariño, M**

*Psychiatrists. Complexo Hospitalario de Pontevedra. Servizo Galego de Saúde (SERGAS)

**Pediatricians. Servizo Galego de Saúde (SERGAS)

\section{anagiago@yahoo.com}

\section{Introduction:}

The health of children and adolescents is an essential factor for the future of a country as well as a determinant of the person's health throughout their life. According to recent studies, the most important cause of disability-adjusted life years (DALYs) is due to psychiatric disorders. Most mental disorders begin during youth. Poor mental health is strongly related to other health problems, lower educational achievements, substance abuse and violence (1) (2). The adequate treatment of ADHD, the most frequent diagnose in Galicia, is associated with reduction in the risk for subsequent drug and alcohol use disorders (3)

Objective:

This study reviews the epidemiology of child and adolescent mental health problems and the situation of mental health services for this population in Galicia and other Spanish regions.

Methods:

-We studied the most recent epidemiology data about mental health in children and adolescents in Galicia (4)

We decided to compare the Galician Mental Health services for young people with those of other regions in Spain. To compare Galicia with other regions in Spain we chose 9 more regions: 3 with similar GPD: gross domestic product (Asturias, Valencia and Castilla-León); 2 with a slightly higher GPD (Rioja and Catalunya); 2 with the highest GPD in Spain (Euskadi and Madrid) and 2 with a lower GPD (Extremadura and Andalucía). We made an up-to-date review of services offered in Galicia and other Spanish regions using official statistics, research papers and an analysis of different policies throughout the Country and Europe.

-Third, we study epidemiological variables closely connected with mental health: suicide, suicide in young people, car accidents, drop outs in school, substance abuse.

Results:

-In Galicia the epidemiological studies reported a prevalence rate of moderate-to-serious yychiatric disorders between $0-14$ years old of $11.5 \% \mathrm{Cl} 95 \%$. The prevalence was $4.5 \%(0-5$ years old), $18.5 \%$ (6-10 years old), $22 \%$ (11-14 years old) (4). The most frequent pathologies were ADHD (5.36\%), language disorders (3.42\%), learning disorders (3.26\%), anxiety-depressive disorders (2.4\%) and behavioral disorders (1.875). $47 \%$ showed comorbidity with another mental disorder. Symptoms lasted a median of 25 months. Most of the cases required attention by multiple educational, social, healthcare professionals. The prevalence of the psychiatric disorders in children and adolescents between 0 to 14 increases with age. We find that $22 \%$ of children 10 and above suffer from disabling mental illness (4). The most frequent diagnosis is ADHD (4), chronicity is the norm and in $44 \%$ of the cases, the Public Health system was not enough to treat these children.

-Although the prevalence of mental health problems in Galicia are similar to other regions, Mental health public services for children and adolescents are inadequate in Galicia compared with other regions in Spain (5). the number of psychiatrists is below the Spanish media, there are not day hospitals for adolescents and after 15 years old, patients are treated in adult units. The populatio in Galicia is decreasing, in the last 5 years we have lost 70,000 population, many young people have emigrated and the natality rate is one of the lowest in Europe (6). Galicia leads deaths related to alcohol misuse and suicide in young people, ranks second in death by suicide at any age and has one the highest death rates in traffic accidents in Spain (6). In Spain suicide is the third leading cause of death in the age group from 15 to 29 years (7).
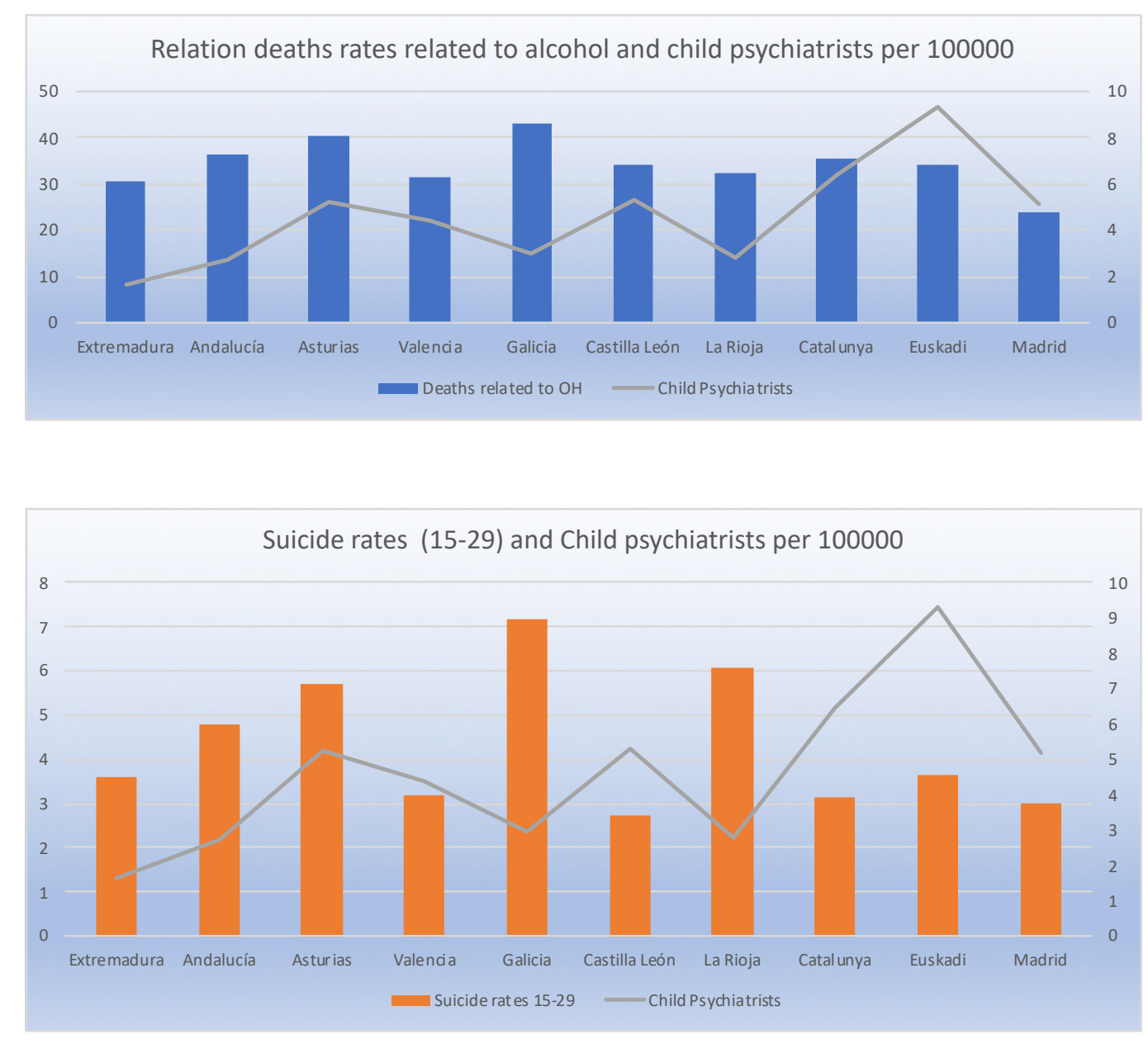

Bibliography

1. Patel V, Flisher A, Hetrick S, McGorry P. Mental health of young people: a global public-health challenge. Lancet. 2007 Apr; 14(369): p. 1302-1313.

2. World Health Organization. WHO report 2000

3. Wilens T, Faraone S, Biederman J, Gunawardene S. Does stimulant therapy of ADHD beget later substance abuse? A Meta-analytic Review of the literature. Pediatrics. 2003; 111: p. 179-185.

4. Carballal-Mariño M, Gago-Ageitos A, Ares J, Rio Md, Garcia-Cendon C, Goicoechea-Castro A, et al. Prevalence of neurodevelopmental, behavioural and learning disorders in Pediatric Primary Care. An Pediatr. 2018 sep; 89(3): p. 153-161.

5. Arango C. Libro Blanco de la Psiquiatría del Niño y del Adolescente en España Madrid: Fundación Alicia Koplowitz; 2014

6. INE. Spanish Institute of Statistics 2017

Navarro-Gómez N. Suicide among young people in Spain: Facts and possible causes. An analysis of latest data available. 2017 March; 28(1): p. 25-3

B. Kieling Cac. www.lancet.com. [Online]; 2011 .

9. Butler M, MP. Current issues in Mental Health in Canada: Child and Youth Mental Health. Ottawa: Lybrary of Parliament; 2014.

\begin{tabular}{|c|c|c|c|c|c|c|c|}
\hline $\begin{array}{l}\text { Regios } \\
\text { in Spain }\end{array}$ & $\begin{array}{l}\text { Range of ages } \\
\text { cared for at } \\
\text { Child and } \\
\text { adolescents } \\
\text { units }\end{array}$ & $\begin{array}{l}\text { D a y } \\
\text { Hospit } \\
\text { a } \quad 1 \\
\text { capaci } \\
\text { ty } \\
\text { ratio } \\
\text { p e r } \\
10000 \\
0\end{array}$ & $\begin{array}{l}\text { Number of } \\
\mathrm{c} \mathrm{h} \text { i I } \mathrm{d}- \\
\text { adolescent } \\
\mathrm{s} \\
\text { psychiatris } \\
\text { ts } \\
\mathrm{p} \text { e r } \\
100.000\end{array}$ & $\begin{array}{l}\mathrm{Ch} \mathrm{hild} \\
\text { adolelescents } \\
\text { psychologie } \\
\text { s } \\
100.0000\end{array}$ & $\begin{array}{l}\text { Number of beds } \\
\text { child-adolescen } \\
\text { psychiatry in publil } \\
\text { general hospital } \\
\text { per } 100000\end{array}$ & & $\begin{array}{l}\text { oss } \\
\text { mes } \\
\text { mes } \\
\text { odu } \\
\text { od } \\
\text { D) }\end{array}$ \\
\hline Galicia & $0-15$ & None & 2.98 & 3.11 & 2.07 & & $22497 €$ \\
\hline Asturias & $0-15$ & Yes? & 5.25 & 5.46 & 3.66 & & 2204 \\
\hline Valencia & $0-15$ & $\begin{array}{l}\text { Yes? } \\
\text { e }\end{array}$ & 4.40 & 3.69 & 2.85 & & $22055 €$ \\
\hline Madrid & $0-18$ & 14.59 & 5.17 & 3.50 & 3.25 & & $33809 € €$ \\
\hline $\begin{array}{l}\text { Cataluñ } \\
\text { a }\end{array}$ & $0-18$ & 31.50 & 6.42 & 14.06 & 4.35 & & 2993 \\
\hline $\begin{array}{l}\text { Extrema } \\
\text { dura }\end{array}$ & $0-18$ & None & 1.65 & 2.19 & & & 1726 \\
\hline $\begin{array}{l}\text { Andaluc } \\
\text { ía }\end{array}$ & $0-18$ & 19.01 & 2.72 & 2.45 & 0.70 & & 1847 \\
\hline $\begin{array}{l}\text { Castilla } \\
\text { Leoon }\end{array}$ & $0-18$ & 2.88 & 5.32 & 3.89 & 2.30 & & 2355 \\
\hline La Rioja & $0-18$ & None & 2.79 & 5.58 & 3.72 & & $26044 €$ \\
\hline Euskadi & $0-18$ & Yes? & 9.28 & 8.54 & 5.89 & & $33088 €$ \\
\hline
\end{tabular}

\section{Conclusions:}

-The prevalence of mental health problems is similar worldwide (2)

•Children and adolescents' mental healthcare investment yields high returns in terms of developmental potential realized, adult disorder prevented or less severe, and economic advantage for healthy individuals (8).

- Mental health problems are associated with lower academic achievement, greater family distress and conflict, and poorer social functioning during childhood and into adulthood.

-Psychiatric treatment varies greatly among different regions in Spain despite Spanish Health System's claimed equity across regions.

-Child-Psychiatry is still not recognized as a medical specialty in Spain.

-In Galicia, psychiatric care of children and adolescents is handled mostly by social and educational services. A clear indicator of this systemic problem is that across the region only seven beds are allocated for child-adolescent psychiatry in public general hospitals, however, children and adolescents juvenile centers allocate 71 beds. The juvie facilities, often located in remote rural areas, giving a marginal attention (this is against the modern psychiatric reform) Children's mental health must be an integral component of in health settings. Additionally, most resources used to treat behavioral, psychotic, eating and anxiety disorders rely on social, educational and endocrinological services, they are not part of mental health services.

-Galicia registers the highest mortality rate related to alcohol consumption and suicide before 30 and it is the second in suicide rate in the country

-We found a surprising lack of adequate investment in child-adolescent mental health services. We can find much more attention places for young people with serious mental disorders in "correctional centers" than in mental integrated services, for example,

-The study suggests a connection between inadequate children and adolescents' mental healthcare investment and Galicia's poor performance in healthcare indicators. 